\title{
Face Negotiation Theory: A Critical Analysis Of Hijab (Veil) Among Muslim Women In Pakistan
}

\author{
Tehsin Azhar \\ \& \\ Qaisar Khan \\ National University of Modern Languages Islamabad \\ Arab Naz \\ Department of Sociology \\ University of Malakand
}

\begin{abstract}
The practice of hijab (veiling) among Muslim women has triggered a great deal of scholarly exploration and debate. This research puts forward empirical evidence to clarify the perception of people about appearance and veil in Pakistani context and highlights the conflicting meanings and purposes of veil among people belonging to different strata of society. With the increasing popularity of veil among Muslim women not only motivated religious scholars to get into this matter holistically but also prompted sociolinguists to explore the reality. Informed by face negotiation theory and social semiotics, this study unveils the ideological implications of wearing hijab. To dissect the reality, the research has been carried out at two levels. First, it examines the perspective of observers through questionnaire and second, it investigates the ideology of women who do/don't wear hijab through short interviews. Specifically hijab is assumed to draw a line among different strata of Pakistan on one hand while on other, in strict sense it creates a gap between exclusion and inclusion of women in Islamic/Muslim community.
\end{abstract}

Keywords: Hijab (veil), Islam, Social Semiotics, Personal Appearance.

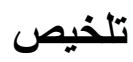

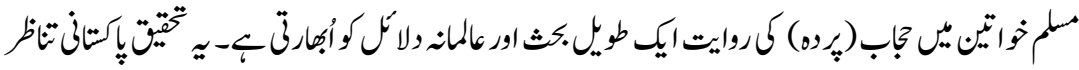

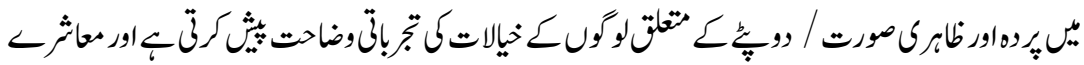

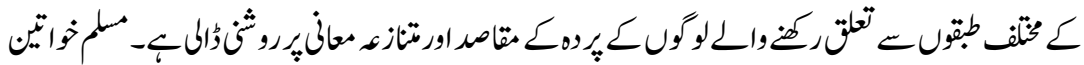

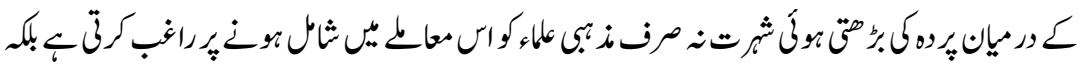

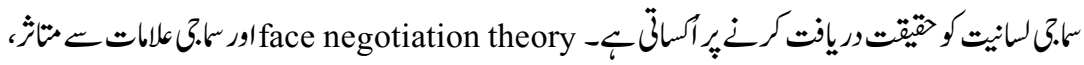

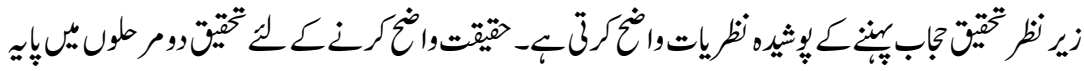

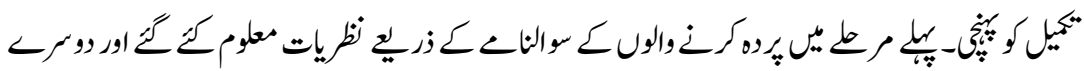

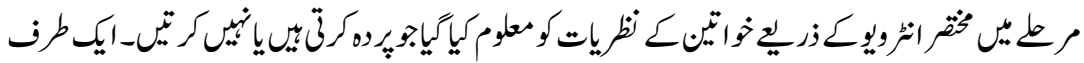




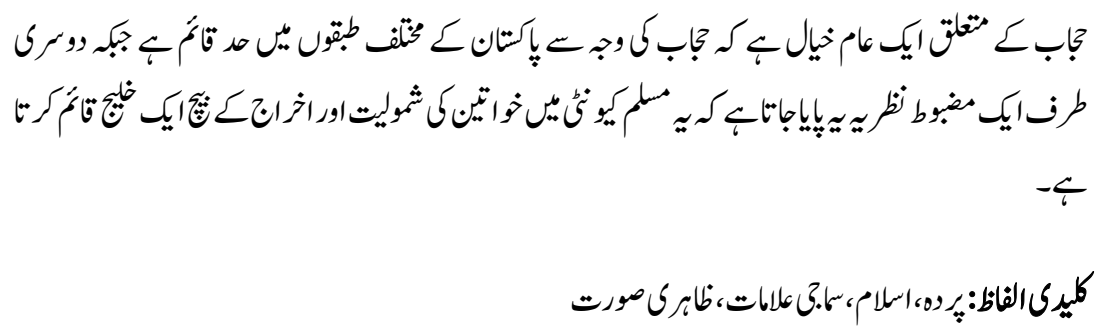

\section{Introduction}

Appearance creates and thus communicates meaning (Knapp, Hall \& Horgan, 2013). Everyday people derived first impressions about others from the way others present themselves (Read \& Bartkowski, 2000). As a salient but nonverbal aspect of communication, it significantly affects the course of relations and perceptual thinking. Although beyond the scope of the current study, the importance of kinesics, proximics and chronemics cannot be overlooked (Burgoon, Buller \& Woodall, 1989). Informed by face negotiation theory, this study argues that we encode messages through our appearance and observers decode it (Knapp, Hall \& Horgan, 2013). More specifically, veil or hijab or purdah in the context of the study is tied up with messages particular to the local culture. The decoding process is in large part determined by the observer's background i.e. age, gender, education, residence and culture however. Historically, hijab is interpreted as a means to subjugate women and to distance them from public life (Read \& Bartkowski, 2000). It is argued that there are other culture specific faceworks that inform our appearance and the existence of hijab and its survival therefore need further investigation. The core questions that this study attempts to answer are: Why women do/don't wear veil? What do they intend to encode and how is that message decoded by others in different socioeducational contexts?

\section{Theory and Context}

According to face negotiation theory, we need to investigate reasons for the way people act, react, communicate and behave in a particular situation. At the core is the internal drive to maintain socially expected and acceptable face- a metaphor for the public image that people display (West, Turner \& Zhao, 2010). There are several factors that determine our behavior including content conflict goal, relational conflict goal and identity-based goals. In order to appreciate the foundation and scope of the theory, we need to recognize the conflict arising out of perceiving ours and other's identities that may threaten, enhance or undermine face. In case of misinterpretation of face, we resort to a set of behaviors (verbal and nonverbal) more appropriate to restore the face loss summarized in the term, 'facework'. The way we perceive and interpret the situated meaning of face and 
our endeavors to enact facework depend on the cultural context in which we survive (Oetzel \& Ting-Toomey, 2003).

The theory is based on several assumptions where some of them found more relevant to the current study are contextualized to understand and appreciate the basic questions that guide the study. A leading assumption is that people try to maintain and negotiate face in communication which implies that we interpret the opinion of other people around us and then attempt to take measures to make our face more neutral or appropriate for the situation. Another assumption is the cultural variability dimensions of individualism-collectivism that primarily differentiate between two polarized forms of culture. First, individualistic culture values individuals over the larger society and second, collectivistic culture places emphasis on group affiliation over individuals (West, Turner \& Zhao, 2010). Based on individualism-collectivism dichotomy, is another important assumption of face negotiation theory according to which people prefer self-oriented or otheroriented facework. Put another way, members of individualistic culture value their own face while in collectivistic culture; they strive to create a positive face for the group and not just themselves. In the context of the study, it is therefore argued that the practice of veiling may be more extrinsic than intrinsic. In other words, the one who decodes the message is more important than the encoder. Further, the interplay of cultural expectations and collectivism overrides individual preferences (Oetzel \& Ting-Toomey, 2003).

In semiotics, we usually construe things as signs (signifier) and unconsciously connect them to the most familiar system of conventions to impart relative meaning to that specific sign (signified) which we usually observe in our surrounding (Culler, 1986). To illustrate, in Indian culture white dress is sign of mourning and lamentation and Hindus wear white dress on death ceremony (Miller \& Hamell, 1986) while Christians associate white dress with marriage. It is significant use of signs which is the core concern of semiotics. In this respect two notable models are proffered by the Swiss Linguist Ferdinand de Saussure and the American Philosopher Charles Sanders Peirce. Saussure has presented his "dyadic" or two-part model (Chandler, 2002) wherein he has formulated the psychological concepts of signifier and signified. The signifier can commonly be interpreted as the things which can be seen, heard, felt, touched or tasted. On the other hand, Peirce has proposed his model, composed of three basic components and it is named as triadic model. The three basic components of this model are 'the representamen' (signifying element), 'an Interpretant' and 'an object'. In his model of Sign, he has clearly elaborated the relationship of the above three mentioned components. Sign is representamen, object is a thing which is affected by sign and interpretant is the idea which affects the object. Thus, we can say that red light faced by the traffic is representamen, traffic (object) and the idea that red light indicates that the vehicle must stop is interpretant (Cobley, 2005). Pierce 
believed that not every quality of an object carries productive signification. It can be only a part or some qualities which can enable a sign to signify it while interpreter has some previous history or knowledge that helps him relate that particular sign with some other signs (Hiltunen, 2008). Similarly, appearances including veil serve as sign that trigger signification (encoding) which enable interpreters to infer various meanings based on previous experiences or perceptions (decoding).

In the theoretical perspective of face negotiation and semiotics, appearance thus constitutes a dominant source of visual impact and symbolic signaling. Also it emerges as a major component of individual personality and the essence of whole society tied up to a particular culture. It plays a central role in interpreting selforiented and other-oriented human behaviour. Leathers \& Eaves (2008) are of the view that physically attractive individuals with socially acceptable appearance are better benefited by their surrounding while Kaiser, Nagasawa \& Hutton (1991) argue that alluring individuals are mostly liked by others and they can have better opportunities of getting good jobs and have more social dynamics than others. In interpersonal communication, individuals try to build their identity and social solidarity through their appearance. In fact they do not say to another person, 'I want to impress you' or 'I want to dominate you' but such messages are intended through visual appearance and dressing of those we encounter in a communication situation (Leathers \& Eaves, 2008).

\section{Human Language and Sartorial Language}

Our dress, language and behaviour are symbolic codes; they convey meanings that are not straight forward. They generate our identity, reflect our ethnic beliefs and clarify our socio-economic standing. In another sense, human language (use of vocabulary, tone, intonation, silence etc) and sartorial language (what our appearances or dresses communicate) are the main contributors in creating, preserving and reinforcing our social identities. They are also pivotal to ranking and thus inequality in society. The socio-historical analysis of power hierarchy in Pakistan reveals dominance of the rich over the poor; the urban over the rural; and the westernized over the ethno-nationalism. Amid these polarized identities, language and appearance have been significant markers at symbolic level. Based on them, one can easily identify linguistic and dress pattern for a typical bureaucrat; a clerk; a young elitist and/or a member of lower middle class. Language both human and sartorial defines the role of human beings as dominant or recessive models of society. The concept of dressing and more specifically "power dressing" is not new. Medieval paintings display a novel scenario of power dressing in which Mughals who ruled the sub-continent for about three hundred years are seen with robes and cloaks while the British rulers brought with them a set of English dresses and language that became symbolic of the ruling 
elite. Indians under the British rule started wearing English dresses because they wanted to show themselves as the desirable part of the British rule (Rahman, 2010). In the backdrop of the argument, dress therefore employ a strong impact in explicating the impression as one wants to construct or to impress others and dressing justifies our dominance, likability, interpersonal engagingness and credibility (Litosseliti, 2014). For example uniforms create a specific impact and sometimes desirable qualities are referred to the wearer (Swain: 2002). It is also related to power, discipline, authority and dominancy.

\section{Conflicting Views on Purdah System}

Like all other forms of appearance, veiling or hijab or purdah also disseminate messages and evoke different responses. It therefore is integral to determine and thus represent women's cultural identity. Purdah System has been the topic of boisterous altercation between the old bourgeois school of thought and modern enlightened strata of Muslims who have been brought up under the influence of western culture. Old fashioned Muslim society defend the system as integral to Islamic conception of gender identity and segregation while the modern and liberal democratic Muslims consider the system as discriminatory and symbolic of male domination. Also they do not disapprove life in early Islamic society portrayed in fashionable and modern circles of New York and London. Instead of debating the social significance of the system, the truth has vanished somewhere amid broader inconsequential controversies (Ahmad, 2003). On the other hand, Europeans carry a different point of view about veil. For them, it carries a value which is politically significant and symbolizes the amorous mysteries of the east (Young, 2005).

With a view to reinvent the actual debate, the study is an attempt to investigate the nature and importance of hijab and to highlight the conflicting views and meanings as deduced from hijab in Pakistani society. It attempts to see veiling from the perspective of the respondents to unveil perceptions and attitudes towards veiled women. An effort is also made to investigate reasons and interpretations that justify a revolt against the system.

\section{Methods and Procedure}

The findings of the study are based on the data collected at Bahauddin Zakariya University Multan through questionnaire and short interviews.

\section{Location}

The university is located in the densely populated city of Multan, in the Punjab Province of Pakistan. It has a history of offering education both in religious and secular subjects. The university has several departments that disseminate 
knowledge at undergraduate and postgraduate levels in religious studies; literature; languages; biological, medical, physical, computer and management sciences. The number of students enrolled in the university is in thousands.

\section{Population}

The students enrolled in the university belong to diverse socio-economic and ethnic background. They include students from all the provinces of Pakistan. The female students and teachers include the two polarized (veiled/unveiled) groups who peacefully co-exist. Like the rest of the society, the two mindsets mostly go unnoticed particularly in the urban centers where a considerable number of women belong to the two groups. There are however, unpronounced cultural repercussions for both that are investigated in the study as perceived by the participants. Similarly the male population also consists of members who like/dislike the purdah system.

\section{Sample Size}

With a view to generate the research data, a total of two hundred participants participated in the study. One hundred students participated in the quantitative phase i.e. questionnaire while the rest attended short interviews. The participants were randomly selected from five teaching departments including Islamic Studies, English Literature, Arabic, Computer Science and Zoology. They included undergraduate and graduate students and teachers with 50 male and 50 female respondents. The five departments were also randomly selected except for the purposive selection of Islamic Studies and Arabic that were found more close to religion and thus their views were of particular significance to investigate the religious dimensions of purdah system. As said, the hundred participants who responded to the questionnaire included 50 male and 50 female students while short interviews were conducted from 100 female participants with due care for including 50 veiled and 50 unveiled women. The purpose of the study was to find out how the participants viewed, perceived and interpreted the veiled and unveiled appearance of women around them and also to investigate socio-cultural and religious reasons for their approach. The objectives of the study also included why women do/don't wear veil.

\section{Procedure}

After conducting a pilot survey, the method of picture review through questionnaire was employed in the quantitative phase of the study. Pictures were shown to the participants and questions related to pictures were asked that were designed specifically for the study. The participants were instructed about the purpose of the study and they were asked to respond to the questions in relation to the pictures. 
Selection of pictures had been made through library method from newspapers, books and magazines. Camera pictures were also included in the selection with prior approval and permission of the owners. Pictures related to university students or teachers were not selected; therefore the persons in the pictures were unfamiliar to the respondents. The views and opinions obtained were solely based on the personal appearance of the persons in those pictures. For instance, a picture included in the study belonged to a middle class college girl who lived in England. The picture had been taken in a shopping mall. She was wearing Jeans and T-shirt. Besides, her head and face were not covered. She was fashionable and modern in her appearance. In another picture, an urban-based lady was shown. She wore shalwar Qameez (Pakistani national dress for women). Her body was completely covered except for her face and hands. She wore bangles and her head was covered with scarf. In local sense, she projected herself as simple and sophisticated in urban sense. Another picture was of an upper class university graduate living in a city. She wore a thin shawl over her head and her face was not covered. There was also a picture of a less educated rural lower class lady whose had covered her face and only her eyes could be seen. She wore black veil or burqa which was quite common in most of the rural and tribal areas of Pakistan. It was also common among urban areas particularly among religious families.

The findings of the study are based questionnaire and short interviews for open ended questions. Both qualitative and quantitative methods have been used for data analysis and interpretation. Quantitative data was employed to get standardized statistical results while qualitative method was used to interpret attitudinal responses of participants and to evaluate the results.

\section{Data Analysis and Discussion}

As said earlier, the existing literature uphold the role and importance of personal appearance in our daily lives as it is one of the prominent markers of our social class, education, background and personality. Our personal appearance creates choices for people, a constellation of implications that construe what we are and what we opt to construct in the mind of others. The data gathered through questionnaire and short interviews reveal that people attempt to form judgmental opinion of others on the basis of appearance and physical getup. During analysis, it was found that male respondents took greater care in noticing jewelry, bangles, nose pin and ring etc while gait and gaze were equally important for them to in conveying meaning. Overall, those participants who overtly practiced the teachings of religion and specifically the students of Islamic Studies appreciated veiled women and also labeled such appearance as more religious and pious. To them, veiled women knew more about the religion of Islam and their families were positively estimated in their inclination to religion. 
The results showed that male participants estimated social class, followed by education and cultural background respectively while female participants sensed education followed by social class, nationality and cultural background respectively. Some male participants said that they could judge overall personality of others by looking at personal appearance of others. The data explicitly authenticated the general observation about Pakistani society where western dresses like Jeans and shirts were symbolic of modernism, dominance, education, authority and power while eastern dresses like Shalwar and Kameez were symbols of traditionalism, simplicity, patriotism and less often backwardness. Thus, the mere presence or absence of westernized dress influenced the meaning-making mechanism of people.

\begin{tabular}{|l|c|c|}
\hline Options & Male Participants & Female Participants \\
\hline Social class & $56 \%$ & $44 \%$ \\
\hline Education & $36 \%$ & $72 \%$ \\
\hline Nationality & $20 \%$ & $16 \%$ \\
\hline Race & $24 \%$ & $8 \%$ \\
\hline Cultural background & $32 \%$ & $16 \%$ \\
\hline Any other & overall personality $30 \%$ & level of socialization $22 \%$ \\
\hline
\end{tabular}

Table: 1.1 shows the percentage of characteristics that can be estimated by male and female participants by seeing personal appearance of others.

The collected data revealed that the views and attitudes of the respondents corresponded with social identity theory of Henry Tjfel and John Turner (Tajfel, 2010). They had argued that social identity was very useful to identify, categorize and compare people. Likewise, appearance in interpersonal communication also contributed to their social identity. The field data indicated that the respondents attempted to judge and attribute social characteristics to the people in pictures. For instance, majority of the participants ranked the girl in Jeans as belonging to the rich and affluent upper class while those wearing local dresses or wearing veil were categorized in middle or lower middle class. At another level, western dress was interpreted bold, modern, secular and the outcome of westernized education while veil betokened love for religion and a mark of strong familial traditions.

Many participants were of the view that those women who did not wear veil were under the influence of western culture at individual and family levels. Further, such appearances were also ranked urban as many participants were of the view that veil was a phenomenon rarely found in urban areas. Some of the participants explained that religious sentiments were still stronger in rural areas while they were losing ground in urban centers mainly due to modern education and the influence of electronic media. There were differences in the recorded opinions about the perception of veil however. Some female respondents were of the view that society has a set of preconceived notions of religion and identities that had set 
standards for judging women. Some few veiled women were of the view that they wore veil mainly because their family elders wanted it while one respondent was of the view that wearing veil was to secure her from others. Few women were of the view that veil was part of their cultural identity and that religion had made it compulsory for them to keep distance from strangers. Those respondents who were not convinced about the practice of Purdah were of the view that they did not find it difficult to interact and socialize with others without veil.

During the analysis of the questionnaire and interview data, it was found that respondents had disclosed their mental state of mind while interpreting the pictured women. It indicated that posture or demeanor conveyed meaningful messages and information about the personality and state of mind of the observer and the observed. Many of the participants attempted to judge and to predict the state of mind by seeing appearance and posture of others. For instance, open hands, short shirts/Jeans, general relaxation of limbs; hair dressing and use of makeup were reminiscent of dominance, boldness, relaxed and confident personalities. So much so, some female participants also judged the eye makeup of the ladies and were of the view that educated ladies had the sense how to make up and to portray her image to others. Likewise, wrapped hands made the participants to believe that girl was less confident, less educated and also confused. Interesting observations were made by the participants with particular reference to the veiled woman. About $60 \%$ participants considered her backward, forced and even victimized while only $3 \%$ of them opined that the veiled women could be an Islamic Scholar. The rest of the participants did not clearly state their position. To note, those who negatively interpreted the veil were mostly from urban areas and had been studying in modern subjects while absolute positivity was observed mainly in the students who were enrolled in the department of Islamic Studies. At another level, there was considerable variation in the interpretation of veil for women. Some participants were of the view that veil implied complete physical segregation and hiding of all body while some were of the view that a mere covering of the head was all that mattered for women. There were also participants who did not agree with either of the two interpretations. They were of the view that it was not necessary for women to strictly observe purdah in traditional sense. Theoretically, the "purdah" system among Muslims has been the subject of intense altercation between traditional, reactionary, old and conservative school of thought and new, modernized, liberal and enlightening sections of Muslims. As observed, there are different reasons of wearing veil. It is affiliated with geographical organization and social status. In some areas of Pakistan, upper class woman tend to wear veil while lower class woman usually move around without veil.

During the course of interviews, a female respondent Sara found cultural reasons for veiling. She said, 'I wear veil because of my family background. I belong to a 
rich feudal family and it is obligatory for us to wear veil as it is sign of dignity and prestige in our locality'. Some of the participants gave more importance to their security and were of the view that they preferred veiling because that would prevent others to recognize and estimate their identities. Some female respondents also revealed that their parents would not allow them to more around and study without veil. The security perspective also points to the patriarchal social structure and male dominance in Pakistani society. One dominant view supported by research studies relate to gender role segregation and delimiting women to domestic sphere only. This mindset is also a major reason of low literacy among females in the country. In other words, the tribal and rural sub-cultures in Pakistan which constitute about $70 \%$ of the total population predominantly idealize domestic chores for women and discourage their participation in public life. It is the same argument that advocates gender segregation in social roles. Women are idealized for reproductive role, to take care of children and other household activities while men are idealized for their role as the sole bread winner for the family. According to Naila, a female student of Islamic Studies, women should better keep their personal identities hidden from the general societies to avoid risking her personal security and family reputation. In her own words, 'Women have to spend a lot of time in their homes due to which they do not understand the society in a better way as compared to men, so women should veil for their own security'. Hessini (1995 as cited in Bullock, 2002) has also argued that veil is a symbol of interiority because woman has to spend her time in home and when she moves exterior she should wear veil to create equilibrium in society.

Historically, Pakistani society has been under the influence of the religion of Islam. Majority of the Muslims practice and follow religious instructions. It was also supported during the interview process. A considerable number of participants did not go against veil due to religion. The varied in interpretation of the concept of veil however. In an interview with Shameem, she attempted to mix culture and religion and was of the view that women should wear Pakistani clothes and should represent Islamic culture. Likewise, another interviewee was of the view that those women who observed purdah were true believers. She also recited the following verses of Holy Quran: 'O, Prophet! Say to your wives and daughters and women of the believers that let down over them their hijab (over garments), that will be more proper that they may be known and thus they will not be molested'. On female student insisted that 'veil is one of the best Islamic rule to secure themselves from men' while another interviewee said, 'I observe purdah as a habit. I have been doing it since my childhood days. I think that it is good for women to wear veil. It is not justified to link it to educational accomplishments. A veiled woman can progress in education and can opt for a prestigious profession like lawyer or doctor. I want to present myself as an example to prove that although I wear veil, I also perform my duties and do all sorts of jobs of my life perfectly by following Islamic teachings'. While explaining specific reasons 
behind wearing veil, Natasha a young and talented female student was of the view that she did not approve of the strict observance of Purdah particularly in educational institutions but she had to wear veil to please her in-laws. She further added that her fiancé liked it and had asked her to observe purdah. Before engagement, she did not even cover her head, she explained. Some interviewees observed that veil served as a safety shield as it prevented others particularly men to have a glimpse of her jewelry, clothes and makeup. According to them, women were mostly treated as sex objects and veil therefore had a significant role to ward off masculine assault.

One important dimension of the investigation during the study was to find out why women did not wear veil? The data revealed that the modern trends and adaptation to modernized culture under the influence of electronic media were in the main responsible for encouraging women not to wear veil. One female respondent named Sobia told that she did not wear veil because she had been teaching in an American school where they encouraged female workers to be neat and clean. They also did not encourage veiling that made her relinquish it. She further explained that it was mainly because she wanted to secure her job and to survive in that particular workplace. Another female respondent Ayesha pointed to the reality of glamour in modern life. She was of the view that everyone tried to look better, smarter and more socially acceptable. Another lady named Shazia asserted that she wanted to look pretty and graceful and she believed that veil could spoil her image in front of other mates who belonged to upper strata. Rahman (2014) has also claimed that people in western dresses get higher rank in society and score higher in power hierarchy. In other words, western dresses send messages that the wearer is rich, educated, modern, urban and not traditionbound. In her reply to the merits of wearing / not wearing veil, Ayesha did not disapprove of either but shared her practical experiences. In her words, 'I had the experience of veil in my past; I think it does not really affect your performance. But when I used to wear veil, people normally considered me conservative and reserved and without veil I was, according to many fellows, moody, funny, fresh, happy and bold'. She wanted to prove that there are socio-cultural practices that may not affect you in person but may have meaningful messages for others around you. With a view to better negotiate your face then, you have to care for societal preferences.

On the hand, there were other female students who did not wear veil but unlike others they did not justify their appearance. They were of the view that veil was a compulsory component of the religion of Islam and those who did not follow it were away from their religious selves. For instance, Huma believed that her parents did not teach her the true essence of Islam that was why she did not wear veil. She said that her parents would tell her to say prayer but that was just the recitation of some verses. She was not taught how to behave as a grown up lady 
and thus she did not succeed in grasping religious teachings related to purdah. She further explained that there were many other female students who did not know the true spirit of purdah and they interpret it under the influence of modern media where there is less space for veiled women.

\section{Conclusions}

The research study was undertaken to investigate societal perceptions and attitudes towards veiled / unveiled women. An important reason for conducting the study was to ascertain the reasons of wearing veil. The study was based on the role and importance of personal appearance in our daily lives as one of the prominent markers of our social class, education, background and personality. Questionnaire and short interviews were informed by social semiotics and face negotiation theory. Also important was the realization that non-verbal messages contained in appearances created choices for observers on the basis of which they estimated or formed first impression about the observed. While assuming a guise, we also form a constellation of implications that construe what we are and what we opt to construct in the mind of others.

The data gathered through questionnaire and short interviews revealed that people attempt to form judgmental opinion of others on the basis of appearance and physical getup. This research clarifies most of the issues related to veiled and unveiled women. $60 \%$ participants considered veiled women as backward, forced and victimized; only $3 \%$ participants who had religious background and belonged to Islamic Studies Department opined that veiled woman could be an Islamic scholar.

Certainly, Nonverbal cues are one of the best, important and analytical parts of our communicative endeavors. Nonverbal cues such as gestures, posture, attire, eye gaze etc communicate how we feel and how we want to be viewed by others. Appearance, being a part of nonverbal cues, veiled and unveiled women send nonverbal messages and different individuals interpret it in a different manner. This encoding and decoding of messages occur at varying degree of awareness and background. Most of the research participants believed that girls in western attire were more confident, educated, cultured, rich and mannered while girls with eastern looks were perceived as simple, tradition-bound, depressed, coward and sometimes economically poor and illiterate. Research participants with religious background appreciated veil and some participants commented on veiled women as 'religious scholar' while some other mocked veiled women and called them 'sisters of Jamat-e-Islami' or 'Taliban group'.

With particular reference to face negotiation theory, it was found that some women wanted to convey the feelings of religiosity and virtue and they saw veil 
an important part of public appearances of females. There were other women who observed purdah but for reasons more cultural and familial than religious. They would prefer veil mainly because their family or in-laws would like to see them veiled. With reference to the true spirit of veiling in Pakistani society, no uniform views were found and the respondents did not agree in its definition. Some were of the view that veil implied complete covering while some interpreted it as covering of head only.

\section{References}

Ahmad, N. (2003). Women in Islam. New Delhi: APH Publication Corporation.

Bullock, K. (2002). Rethinking Muslim women and the veil: Challenging historical \& modern stereotypes. Herndon, VA: IIIT.

Burgoon, J. K., Buller, D. B. \& Woodall, W. G. (1989). Nonverbal Communication: The unspoken dialogue. New York, NY: Harpercollins College Division.

Chandler, D. (2007). Semiotics: The Basics (2 ${ }^{\text {nd }}$ ed.). New York, NY: Routledge.

Cobley, P. (2005). The Routledge Companion to Semiotics and Linguistics. New York, NY: Routledge.

Culler, J. D. (1986). Ferdinand de Saussure. New York, NY: Cornell University Press.

Hiltunen, E. (2008). The Future Sign and its Three Dimensions, Futures, vol.40:3, pp. $247-260$.

Kaiser, S. B., Nagasawa, R. H. \& Hutton, S. S. (1991). Fashion, postmodernity and personal appearance: A symbolic interactionist formulation. Symbolic Interaction, vol.14:2, pp.165-185.

Knapp, M., Hall, J. \& Horgan, T. (2013). Nonverbal Communication in Human Interaction ( $8^{\text {th }}$ ed.). Boston, MA: Wadsworth.

Leathers, D. \& Eaves, M. (2008). Successful Nonverbal Communication (4 ${ }^{\text {th }}$ ed.). Boston, MA: Allyn and Bacon.

Litosseliti, L. (2014). Gender and Language Theory and Practice, Abingdon: Routledge. 
Miller, C. L. \& Hamell, G. R. (1986). A New Perspective on Indian-White Contact: Cultural Symbols and Colonial Ttrade. The Journal of American History, pp.311-328.

Oetzel, J. G. \& Ting-Toomey, S. (2003). Face Concerns in Interpersonal Conflict a Cross-Cultural Empirical Test of the Face Negotiation Theory. Communication Research, vol.30:6, pp.599-624.

Rahman, T. (2010). Language Policy, Identity, and Religion: Aspects of the Civilization of the Muslims of Pakistan and North India. Chair on Quaid-iAzam \& Freedom Movement, National Institute of Pakistan Studies, Quaid-i-Azam University, available online at: http://www.tariqrahman.net/content/scholorly_articles/lan_polocy.pdf

Read, J. n. G. \& Bartkowski, J. P. (2000). To Veil or not to Veil? A Case Study of Identity Negotiation among Muslim Women in Austin, Texas. Gender \& Society, vol.14:3, pp.395-417.

Swain, J. (2002). The Right Stuff: Fashioning an Identity through Clothing in a Junior School, Gender and Education, vol.14:1, pp.53-69.

Tajfel, H. (2010). Social Identity and Intergroup Relations. Cambridge: Cambridge University Press.

West, R. L., Turner, L. H. \& Zhao, G. (2010). Introducing Communication Theory: Analysis and Application. Boston: McGraw-Hill.

Young, R.J.C. (2005). Postcolonialism. Karachi: Oxford University Press.

Tehsin Azhar is Ph.D Scholar in the National University of Modern Languages Islamabad.

Qaisar Khan is Ph.D Scholar in the National University of Modern Languages Islamabad.

Dr. Arab Naz is an Associate Professor in the Department of Sociology, University of Malakand. 